\title{
What is the impact of multi-professional emergency obstetric and neonatal care training?
}

\author{
Anne-Marie Bergh, Shisana Baloyi, Robert C Pattinson \\ MRC Maternal and Infant Health Care Strategies Unit, Obstetrics and Gynaecology \\ Department, University of Pretoria, South Africa
}

Corresponding author: Robert C Pattinson, MD, FRCOG, FCOG (SA)

MRC Maternal and Infant Health Care Strategies Research Unit, Department of Obstetrics

and Gynaecology, University of Pretoria, Private Bag X323, Arcadia 0007, South Africa; email: robert.pattinson@up.ac.za

Anne-Marie Bergh, $\mathrm{PhD}$

e-mail: anne-marie.bergh@up.ac.za

Shisana Baloyi, MBChB, CML (Law), CRIA(Theol.), Dip.Obst, F.MAS, Dip.MAS, PGDip.FamMed , MMed(O et G), FCOG(SA)

e-mail: shisana.baloyi@gmail.com 


\begin{abstract}
This paper reviews evidence regarding change in healthcare-provider behaviour and maternal and neonatal outcomes as a result of emergency obstetric and neonatal care (EmONC) training. A refined version of the Kirkpatrick classification for programme evaluation was used to focus on change in efficiency and impact of training (levels 3 and 4). Twenty-three studies were reviewed - 5 randomised controlled trials, 2 quasi-experimental studies and 16 before-and-after observational studies. Training programmes had all been developed in highincome countries and adapted for use in low- and middle-income countries. Nine studies reported on behaviour change and 13 on process and patient outcomes. Most showed positive results. Every maternity unit should provide EmONC teamwork training, mandatory for all healthcare providers. The challenges are: scaling up such training to all institutions; sustaining regular in-service training; integrating training into institutional and health-system patient-safety initiatives; and 'thinking-out-of-the-box' in evaluation research.
\end{abstract}

Key words: maternal mortality and morbidity; neonatal mortality and morbidity; emergency obstetric care; team training; patient outcomes; Kirkpatrick levels of programme evaluation 


\section{ABBREVIATIONS}

ACNM

AGOTA

AIP

ALARM

$\mathrm{ALSO}^{\circledR}$

AOI

BeMONC

CeMONC

CRM

EmONC

HIC

HIE

LMIC

LSS

LSS-EOC and NC

LSTM

MOET

NVOG

OBCTT

PROMPT

PRONTO

QUARITE
American College of Nurse-Midwives

Association of Gynaecologists and Obstetricians of Tanzania

ALARM International Program

Advances in Labour and Risk Management

Advanced Life Support in Obstetrics

Adverse Outcomes Index

Basic emergency obstetric and neonatal care

Comprehensive emergency obstetric and neonatal care

Crew resource management

Emergency obstetric and neonatal care

High-income country

Hypoxic-ischaemic encephalopathy

Low- and middle-income country

Life-saving skills

Life Saving Skills - Essential Obstetric and Newborn Care Training

Liverpool School of Tropical Medicine

Managing Obstetric Emergencies and Trauma

Dutch Society of Obstetrics and Gynaecology

Obstetric Crisis Team Training Program

PRactical Obstetric Multi-Professional Training

Programa de Rescate Obstétrico y Neonatal: Tratamiento Óptimo y

Oportuno

QUAlity of care, RIsk management, and TEchnology in obstetrics 
RCOG

$\mathrm{RCT}$

SaFE

TeamSTEPPS

UK

US

WHO
Royal College of Obstetrics and Gynaecology

Randomised controlled trial

Simulation and Fire-drill Evaluation

Team Strategies and Tools to Enhance Performance \& Patient Safety

United Kingdom

United States

World Health Organization 


\section{INTRODUCTION}

Maternal and perinatal mortality remain major challenges to health systems globally, especially in low- and middle-income countries (LMICs) [1-3]. The Millennium

Development Goals 4 and 5 called for the reduction of under-five mortality rates (which includes neonatal deaths) and maternal mortality ratios by three quarters by the year 2015 . Many countdown countries have been unable to make sufficient progress [3,4], with the subSaharan region faring the worst with maternal morbidities and mortalities [5]. Where underfive mortality has been reduced, the rate of decrease in neonatal mortality is much slower [6].

In high-income countries (HICs) reports like the United Kingdom's (UK's) Confidential Enquiry into Maternal and Child Health and the Joint Commission on Accreditation of Healthcare Organizations in the United States (US) identified substandard care and a high incidence of medical errors as the cause of a significant proportion of preventable patient morbidity and mortality $[7,8]$. The uniqueness of challenges in obstetric emergencies demands "excellent teamwork and superior communication skills between multiple medical teams" (p. 40) [9]. One of the root causes cited for substandard care is a threatening organisational culture that undermines teamwork and communication, leading to: confusion in roles and responsibilities; lack of cross-monitoring; failure to prioritise and perform clinical tasks in a structured coordinated manner; and lack of support for healthcare providers $[7,8]$. These failures necessitated a shift in training away from individual technical perfection only to better team co-ordination for patient safety through error management and improved processes [10-13]. Numerous health authorities, institutions involved in maternal, neonatal and child health, and labour wards have developed or are developing emergency obstetric and neonatal care training packages to address the changed training needs. 
Studies on emergency obstetric and neonatal care (EmONC) training have proliferated in the past decade and the challenge of evaluating the impact of these programmes is the large variation in the descriptions of training with regard to content, design, delivery style, and duration $[10,14,15]$. The aim of this paper is to map the landscape regarding training in EmONC skills and to give an overview of the different training programmes, packages and approaches discussed in peer-reviewed research reports. Of particular importance are the kinds of training results available on post-training change in (a) provider disposition or behaviour or (b) organisational impact and patient outcomes with respect to morbidity and/or mortality.

\section{METHODS}

A search of peer-reviewed articles written in English and pertaining to systematic multiprofessional training was conducted for the period 1994 to October 2014. The rationale for the choice of the starting date was the following: an initial Pubmed search did not yield any publication before 1994; Beasley et al's publication on the Advanced Life Support in Obstetrics $\left(\mathrm{ALSO}^{\circledR}\right)$ course appeared in 1994 [16]; and the first publications included in Van Lonkhuijzen et al's systematic review of the effectiveness of training in emergency obstetric care in low-resource environments appeared in 1995 [14]. Databases consulted included PubMed/MEDLINE, CINAHL, Web of Science, Science Direct, Cochrane Controlled Trials Register, Popline, African Journals Online, Directory of Open Access Journals, Google Scholar, TOC Premier, and Health Source: Nursing/Academic Edition. Various Boolean combinations of the following search terms were used according to the combination possibilities allowed in each database: "obstetric*"; "emergenc*”; "basic emergency 
Table 1. Inclusion and exclusion criteria.

\begin{tabular}{|c|c|}
\hline Inclusion criteria & Exclusion criteria \\
\hline \multicolumn{2}{|c|}{ Level of training: } \\
\hline $\begin{array}{l}\text { - Post-basic/postgraduate/resident medical } \\
\text { training } \\
\text { - Post-basic midwifery/nursing training } \\
\text { - In-service training }\end{array}$ & $\begin{array}{l}\text { - Basic/undergraduate medical, nursing or } \\
\text { midwifery training }\end{array}$ \\
\hline \multicolumn{2}{|c|}{ Target audience: } \\
\hline $\begin{array}{l}\text { - Multi-professional/interdisciplinary, but ... } \\
\text { - MUST have included medically trained } \\
\text { participants (e.g. doctors, clinical assistants, } \\
\text { medical assistants, assistant physicians) }\end{array}$ & $\begin{array}{l}\text { - Only one professional group targeted } \\
\text { - Traditional birth attendants } \\
\text { - Community health workers }\end{array}$ \\
\hline
\end{tabular}

\section{Nature of training:}

- Broader ('standardised') training packages including $\geq 3$ " different emergency types considered direct causes of maternal deaths

- Complex interventions with other obstetric quality-improvement activities related directly to or following on the training

- Complementary training approaches where there is evidence of application to specific or unspecified emergency obstetric skills (e.g. clinical obstetric drills, scenarios)

- Training in (an) isolated specific emergency type(s) where information is not presented that it is part of a broader training package

- Obstetric anaesthesia training

- Complementary training approaches without application to obstetric skills (e.g. generic teamwork, communication)

- Training included as only one component of a more comprehensive package with multiple interventions for improving obstetric care

\section{Duration of initial training course:}

- $\leq 2$ weeks continuously

- $\leq 40$ hours in case of time intervals between modules/sessions
- >2 weeks

- Not specified in sufficient detail

Kirkpatrick's four levels of programme evaluation:

- Sufficient information on the programme and some form of results categorisable according to Kirkpatrick's four levels

\section{Types of studies:}

- Randomised controlled trials (RCTs)

- Quasi-experimental studies with or without control group

- Observational pre-post intervention studies

- Qualitative/mixed methods/case studies
- Anecdotal and experiential reports

- Reviews

- Self-reports not part of a study type identified for inclusion

${ }^{*}$ The number in the SaFe study to investigate benefits of different training methods was used as guideline [25] 
obstetric*"; "comprehensive emergency obstetric*”; "obstetric care training"; "train*”; "team"; "fire drill*”; “emergency drill*”; "simulation"; "simulator"; "mannequin*”/ "manikin*”; "shoulder dystocia"; "eclampsia"; "postpartum haemorrhage"; "breech"; "vacuum"; "forceps". Reference lists from relevant publications were also consulted with a view to identifying possible additional studies to include in the review. A supplementary online file provides details of the search flow.

Owing to the heterogeneousness of studies, the complexity of some training interventions, and variations in assumptions, understandings and descriptions of these interventions, inclusion and exclusion criteria were further refined during the review process for facilitating a manageable set of publications. These criteria are summarised in Table 1.

Figure 1 gives a graphic depiction of the search flow and selection of publications. The initial search yielded 4,235 potentially useful articles. After excluding non-English publications and duplicates, the remaining titles and abstracts were screened. Sixty-nine papers were retrieved for further examination and a further 3 papers were included from the bibliographies of the identified papers. After further analysis, 35 peer-reviewed articles representing a total of 23 studies or trials remained for final review. 
Search results: PubMed/MEDLINE,

CINAHL, Web of Science, Science

Direct, Cochrane, Popline, African

Journals Online, DOAJ, TOC

Premier, Health Source

Total: 4,235 (including duplicates)

Papers excluded after screening:

4,166

Papers retrieved for further review:

69

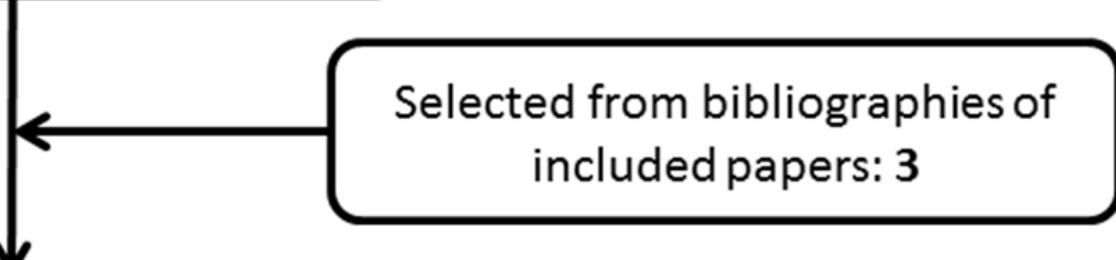

Papers for detailed analysis:

72

Papers excluded after analysis:

37

Peer-reviewed articles

included for final analysis:

35

(representing $\mathbf{2 3}$ studies/trials)

Fig. 1. Search process 
For two of the articles the full papers could not be accessed and their abstracts were included in the analysis $[17,18]$. The results for each paper were tabulated in detail (supplementary online file 2) and tables were created with extracted data for investigating particular aspects of training (supplementary online file 3 ). As the purpose of the review was to map the terrain of EmONC training reports, evidence was not graded.

\section{SYNOPSIS OF PEER-REVIEWED ARTICLES INCLUDED IN THE REVIEW}

The 35 identified peer-reviewed articles represented 23 studies or trials. Ten of the papers were related to the Simulation and Fire-drill Evaluation (SaFE) study and were treated as one intervention [19-28]. Two articles reporting on the Programa de Rescate Obstétrico y Neonatal: Tratamiento Óptimo y Oportuno (PRONTO) trial were included (the pilot study and some of the first results pertaining to changes after the second training module) $[29,30]$. Note was taken of abstracts that demonstrate the real impact of the intervention [31,32], but they were not formally included. Three papers with results from the 'in-house' training in Bristol in the UK were also grouped together [33-35]. A synopsis of the 23 studies analysed is given in Table 2.

The studies comprised five randomised controlled trials (RCTs), two quasi-experimental studies and 16 before-and-after observational studies. Thirteen studies had been conducted in HICs and 10 in low- and middle-income countries LMICs. In terms of geographic spread, three studies had been conducted in the UK, six in the US, three in Europe, one in Australia, one in Latin America, seven in sub-Saharan Africa and two in Asia. The range of hospitals 
Table 2. Synopsis of training programmes and study designs.

\begin{tabular}{|c|c|c|c|c|c|c|c|c|c|c|}
\hline \multirow{2}{*}{$\begin{array}{l}\text { Training } \\
\text { package }\end{array}$} & \multirow{2}{*}{$\begin{array}{l}\text { Study } \\
\text { (name \&/or location) }\end{array}$} & \multicolumn{2}{|c|}{$\begin{array}{l}\text { No. \& level hospitals/ health } \\
\text { facilities in study }\end{array}$} & \multirow{2}{*}{$\begin{array}{l}\text { LMIC / } \\
\text { HIC }\end{array}$} & \multirow{2}{*}{$\begin{array}{l}\text { No. of } \\
\text { articles } \\
\text { in } \\
\text { review }\end{array}$} & \multirow{2}{*}{ Study design } & \multicolumn{4}{|c|}{ Kirkpatrick levels } \\
\hline & & Hospitals & $\begin{array}{l}\text { Health } \\
\text { centres }\end{array}$ & & & & 1 & 2 & 3 & 4 \\
\hline \multirow[t]{4}{*}{ PROMPT } & Bristol, UK [33-35] & $1 \mathrm{TTH} / \mathrm{RH}$ & - & $\mathrm{HIC}$ & 3 & Before-after & & & $3 \mathrm{c}$ & $4 \mathrm{c}$ \\
\hline & SaFE trial, Southwest England [19-28] & $6 \mathrm{DH}(\mathrm{L} 2 \& \mathrm{~L} 3)$ & - & $\mathrm{HIC}$ & 10 & $\mathrm{RCT}$ & & $2 a, b, c$ & $3 b$ & \\
\hline & NHS Foundation Trust, Liverpool, UK $[44,45]$ & - & - & $\mathrm{HIC}$ & 1 & Before-after & & & & $4 b, c$ \\
\hline & Victoria, Australia [46] & 7 & - & $\mathrm{HIC}$ & 1 & Before-after & 1 & $2 \mathrm{a}$ & & $4 c$ \\
\hline PRONTO & Mexico trial $[29,30]^{*}$ & 24 & - & LMIC & 2 & $\mathrm{RCT}$ & 1 & $2 b, c$ & -- & --- \\
\hline \multirow[t]{2}{*}{ AIP } & QUARITE, Senegal \& Mali [36] & $46 \mathrm{RH}(\mathrm{L} 1 \& \mathrm{~L} 2)$ & - & LMIC & 1 & $\mathrm{RCT}$ & & & & $4 b, c$ \\
\hline & Moi Teaching and Referral Hospital, Kenya [57] & $1 \mathrm{TTH} / \mathrm{RH}$ & - & LMIC & 1 & Before-after & & & $3 \mathrm{c}$ & $4 b, c$ \\
\hline ALSO & Kagera Regional Hospital, Tanzania [42] & $1 \mathrm{RH}(\mathrm{L} 2)$ & - & LMIC & 1 & Before-after & & & & $4 b, c$ \\
\hline \multirow{4}{*}{$\begin{array}{l}\text { LSTM- } \\
\text { RCOG LSS- } \\
\text { EOC and } \\
\text { NC }\end{array}$} & AGOTA-NVOG, Tanzania [48] & - & - & LMIC & 1 & Before-after & 1 & $2 \mathrm{~b}$ & --- & --- \\
\hline & Sub-Saharan Africa (7 countries) [49] & - & - & LMIC & 1 & Before-after & 1 & $2 b, c$ & --- & --- \\
\hline & Somaliland, Somalia [50] & 3 & 8 & LMIC & 1 & Before-after & 1 & $2 b, c$ & $3 a$ & $4 b$ \\
\hline & Making it Happen, Bangladesh \& India [52] & $4 \mathrm{DH}$ (Bangl.) & 21 (Bangl.) & LMIC & 1 & Before-after & 1 & $2 a, b, c$ & --- & --- \\
\hline LSS-ACNM & Vietnam $[54]$ & $3 \mathrm{DH} ; 3 \mathrm{FH}$ & 40 & LMIC & 1 & Quasi-experimental & & & $3 c$ & \\
\hline \multirow[t]{7}{*}{ CRM based } & National study, US [58] & 15 & - & HIC & 1 & $\mathrm{RCT}$ & & & & $4 c$ \\
\hline & Beth Israel Deaconness Medical Center, US [59] & $1 \mathrm{TTH}$ & - & $\mathrm{HIC}$ & 1 & Before-after & & $2 \mathrm{a}$ & & $4 b, c$ \\
\hline & Perinatal Safety Initiative, US [60] & $1 \mathrm{TH}$ & - & $\mathrm{HIC}$ & 1 & Before-after & & & $3 a$ & $4 b, c$ \\
\hline & Rhode Island Hospital, US [61] & 1 & - & $\mathrm{HIC}$ & 1 & Before-after & & & & $4 b, c$ \\
\hline & Geneva University Hospital, Switzerland [63] & $1 \mathrm{TTH}$ & - & $\mathrm{HIC}$ & 1 & Before-after & 1 & $2 \mathrm{a}$ & $3 a$ & \\
\hline & TeamSTEPPS, US [18] & $3 \mathrm{CH}$ & - & $\mathrm{HIC}$ & 1 & $\mathrm{RCT}$ & & $2 \mathrm{a}$ & & $4 c$ \\
\hline & OBCTT, Southeast US [62] & $1 \mathrm{TTH}$ & - & $\mathrm{HIC}$ & 1 & $\begin{array}{l}\text { Quasi-experimental } \\
\text { before-after }\end{array}$ & 1 & $2 a, b, c$ & --- & --- \\
\hline \multirow[t]{3}{*}{ OTHER } & CEmONC, Tanzania [17] & $1 \mathrm{DH}$ & & LMIC & 1 & Before-after & & & $3 \mathrm{c}$ & \\
\hline & Copenhagen University Hospital, Denmark [64] & $1 \mathrm{TTH}$ & - & $\mathrm{HIC}$ & 1 & Before-after & 1 & $2 \mathrm{a}, \mathrm{b}$ & $3 a$ & $4 b$ \\
\hline & University of Oporto, Portugal [65] & $1 \mathrm{TTH}$ & - & $\mathrm{HIC}$ & 1 & Before-after & 1 & $2 \mathrm{~b}$ & $3 a$ & \\
\hline \multicolumn{2}{|c|}{$*$ In progress - abstracts not included $[31,32]$} & \multicolumn{4}{|c|}{$\mathrm{DH}=$ district hospital } & \multicolumn{5}{|l|}{$\mathrm{L} 1=$ level 1} \\
\hline \multicolumn{2}{|c|}{$---=$ studies not going beyond Kirkpatrick level 2} & \multicolumn{4}{|c|}{$\mathrm{RH}=$ referral hospital } & \multicolumn{5}{|c|}{ L2 = level 2 (secondary/regional) } \\
\hline \multirow{2}{*}{\multicolumn{2}{|c|}{$\begin{array}{l}\mathrm{FH}=\text { field hospital } \\
\mathrm{CH}=\text { community hospital }\end{array}$}} & \multicolumn{4}{|c|}{$\mathrm{TH}=$ tertiary hospital $/$ medical centre } & \multicolumn{5}{|c|}{ L3 = level 3 (tertiary) } \\
\hline & & $\mathrm{TTH}=$ tertiary an & teaching hos & ital & & & & & & \\
\hline
\end{tabular}


included in the studies spans the whole spectrum from tertiary teaching hospitals to community- and field hospitals. Three LMIC studies included community health centres. As different countries have different classification systems for hospital levels of care and HICs and LMICs were included in the review, no real comparison can be made. Some studies also did not describe the types of hospitals in any detail. However, if one looks at the number of hospitals reached with these studies, only two RCTs included more than 20 hospitals - the PRONTO study in Mexico with 10 institutions in the intervention arm and 14 in the control arm [20] and the quality of care, risk management, and technology in obstetrics (QUARITE) study in Senegal and Mali, with 23 institutions in each arm [36].

All the prominent available EmONC training programmes and packages referred to in the papers identified for this review had been developed in HICs and were adapted for use in LMICs, often in only one or a few healthcare facilities at a time. Training courses or programmes of note are the following:

- Managing Obstetric Emergencies and Trauma (MOET) (no multi-professional training reports) [37-39];

- Advanced Life Support in Obstetrics $\left(\mathrm{ALSO}^{\circledR}\right)[16,40-42]$;

- $\quad$ PRactical Obstetric Multi-Professional Training (PROMPT) [19-28,33-35,43-46];

- Liverpool School of Tropical Medicine (LSTM ) - Royal College of Obstetrics and Gynaecology (RCOG) Life Saving Skills - Essential Obstetric and Newborn Care Training (LSS-EOC and NC) currently run in 11 LMICs in Africa and Asia as 'Making It Happen' [47-53];

- American College of Nurse-Midwives (ACNM) LSS programme [54];

- Advance in Labour and Risk Management (ALARM) with its ALARM International Program (AIP) [55-57]; 
- Programmes based on crew resource management (CRM) derived from the aviation industry with or without the Team Strategies and Tools to Enhance Performance \& Patient Safety (TeamSTEPPS) [18,58-63]; and

- The Programa de Rescate Obstétrico y Neonatal: Tratamiento Óptimo y Oportuno (PRONTO) in Mexico, a combination of a variety of best-practice curriculum inputs covering healthcare simulation and team training $[29,30]$.

There were also reports on three locally developed 'in-house' training programmes offered in Tanzania, Denmark and Portugal respectively $[17,64,65]$. The basic and comprehensive emergency obstetric and neonatal care (BEmONC and CeMONC) training run in many low income countries is often based on the World Health Organization (WHO) training reference manuals $[66,67]$. This is provided when donor support is available (often for multiple interventions simultaneously). There is little follow up on the quality of the training and the long-term supervision of participants in their work environment. We could only find one study from Ethiopia that did not fit our inclusion criteria but that aimed at improving the quality of BEmONC with the intention to do some post-training follow up [68].

In the studies included in the review researchers used different lenses to study EmONC skill training. Not all their training interventions were described in detail and we did not make a detailed comparison between any interventions. To understand differences in training approaches it is useful to differentiate between curricula (sometimes called a training programme), courses and training packages. The curriculum entails what is trained. A course is the application of the curriculum as a stand-alone event to improve individuals' knowledge and skills (e.g. ALSO, MOET and LSS courses that are advertised for professional development purposes; simple EmONC training based on WHO guidelines). A training 
package endeavours to go beyond the objectives of stand-alone courses and can take one of two forms:

(a) A course as part of a multifaceted training- and onsite quality-improvement intervention that includes, for example, audit methodologies and facility-based maternal death reviews (e.g. some of the AIP and 'Making It Happen’ projects) $[36,53,55]$; or

(b) Training as one component of multiple interventions that include other health-systems strengthening activities such as improving emergency transport, infrastructure and user access to EmONC [69-71].

Training sites, modalities and approaches varied across the different studies (details in the online supplementary file 3). Different combinations of onsite ('in-house'/in situ) and offsite training were reported. A few reports mentioned training of the trainers, which had mostly been done offsite. In terms of the bulk training of staff the distribution between on- and offsite training was fairly even. In the HICs most of the training had occurred onsite and in the LMICs all training was offsite, except for the follow-up training in the QUARITE trial [36].

We distinguish between didactic and simulation delivery methods, mostly provided in combination in the training packages. In some studies the didactic lecture-based approach included competency-based classroom teaching enhanced with other interactive activities (e.g. discussions, demonstrations and skills practice). In some studies simulation was further specified as being conducted in a team-training mode. Not all the studies specified the kind of simulation included; some, however, did refer to low-fidelity simulators or training models (mannequins), others to high-fidelity simulators. The PRONTO study uses the phrase 
"highly-realistic, low-tech simulation-based ... training" (p. 2 of 11) [30]. Two studies reported on the inclusion of patient actors in the simulations [21,65]. Only the SaFE study compared high-fidelity- and low-fidelity simulation and concluded that there was no advantage training at a high-fidelity simulation centre (offsite) instead of training onsite using low-fidelity models [23].

Thirteen studies included a team-training approach, with 10 of these mentioning training in communication as well. Emergency drills with scenarios for simulating emergencies have shown to be effective in enhancing teamwork and team communication [33$35,44,46,59,60,30,65,72]$. Six studies reported on repeat- or refresher training sessions. In the Bristol study refreshers took place once every two months and annual attendance was mandatory [33-35]. The SaFE study recommended annual updating for training participants proficient in the management of shoulder dystocia, with more frequent rehearsals for nonproficient performers [26]. The QUARITE trial required recertification once per year and also included a two-year follow-up period with regular outreach visits to the trial hospitals [36].

\section{THE KIRKPATRICK CLASSIFICATION OF EVALUATING TRAINING PROGRAMME}

Kirkpatrick's model of programme evaluation [73] is one of the most popular systems for evaluating training programmes $[74,75]$. A number of studies in the literature reviewed indicated how their authors had evaluated their own programmes according to the four levels of training achievements described by Kirkpatrick [11,14,19,50,63,64,68,76]. The first two levels refer to the reaction of training participants (satisfaction after training) and the 
knowledge and skills learning of the trainee. The third level measures the implementation or application of learned skills and behaviour in clinical practice. The most advanced level relates to the patient effect of training assessed by measurable clinical outcomes $[19,73]$. In order to distinguish more clearly between diverse indicators that are lumped together at one level (e.g. technical versus non-technical skills; objective effect versus subjective perceptions of effect) [77], we refined the Kirkpatrick levels by adding sublevels to levels 2 to 4 . These distinctions make better provision for surrogate markers used to measure actual effect (e.g. administration of an essential drug for team efficiency and patient outcome; or change in staff safety attitudes for behavioural change) $[11,24,78]$.

In the refined classification level 1 remains as is, measuring course-participant satisfaction. Level 2 (learning) refers to the effectiveness of training in providing immediate benefits for individual providers. The sublevels for level 2 are changes in attitudes or perceptions (2a), knowledge (2b) and skills (2c). Most training courses do not go beyond this type of evaluation. Level 3 (behaviour) relates to the efficiency of the training and is measured six months or more after the last training session. We differentiate between provider perceptions of behaviour change (3a), skill retention (3b) and demonstrable changes in workplace behaviour or practice (3c). Level 3c starts measuring beyond individual performance or perceptions and is linked to the performance of the team. Level 4 (outcome) can follow from or be linked with changes in behaviour included in sublevel 3c and includes different types of impact. The sublevels are change in organisation (4a) and change in quality of care and care processes (4b), from which benefits to patients can follow (4c). Patient outcomes are described in terms of a decrease in mortality, morbidity and adverse events. The 'gold standard' for an efficient EmONC training programme would be demonstrably improved 
Table 3. Expanded interpretation of Kirkpatrick's levels of training evaluation.

\begin{tabular}{|c|c|c|c|c|c|}
\hline Level & Description & Questions to answer & Measurement (examples) & & \\
\hline \multirow[t]{2}{*}{1} & REACTION & Is training enjoyable? & & & \multirow{9}{*}{ 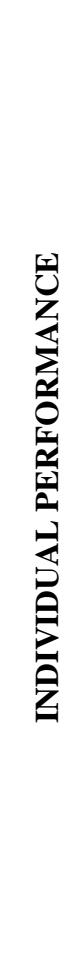 } \\
\hline & $\begin{array}{l}\text { Participation / } \\
\text { Satisfaction }\end{array}$ & $\begin{array}{l}\text { - Trainees' reception of the programme? } \\
\text { (e.g. liking, acceptability, usefulness, relevance) }\end{array}$ & $\begin{array}{l}\text { - End-of-training questionnaire } \\
\text { - Focus groups }\end{array}$ & & \\
\hline 2 & LEARNING & $\begin{array}{l}\text { Is training effective in providing immediate benefits } \\
\text { to healthcare providers? }\end{array}$ & & & \\
\hline $2 \mathrm{a}$ & $\begin{array}{l}\text { Attitudes / } \\
\text { Perceptions }\end{array}$ & $\begin{array}{l}\text { - Change in attitudes? } \\
\text { - Change in confidence, self-efficacy and stress } \\
\text { levels? } \\
\text { - Intent to change behaviour/practice? }\end{array}$ & $\begin{array}{l}\text { - End-of- training questionnaire } \\
\text { - Focus groups }\end{array}$ & & \\
\hline $2 b$ & Knowledge & $\begin{array}{l}\text { - Did learning occur? } \\
\text { - Principles and facts learned? } \\
\text { - Knowledge retention after } \geq 6 \text { months? }\end{array}$ & $\begin{array}{l}\text { - Pre-post training test/questionnaire (e.g. MCQs) } \\
\text { - Repeat of training test/questionnaire }\end{array}$ & & \\
\hline $2 \mathrm{c}$ & Skills & $\begin{array}{l}\text { - Techniques learned or improved? } \\
\text { - Teamwork performance }\end{array}$ & \multicolumn{2}{|l|}{$\begin{array}{l}\text { - Skills improvement: simulated case for skills and teamwork demonstration } \\
\text { - Clinical decision making: written case scenarios } \\
\text { - Teamwork measurement tools }\end{array}$} & \\
\hline 3 & BEHAVIOUR* & Is training [and subsequent reinforcement] efficient? & & & \\
\hline $3 \mathrm{a}$ & $\begin{array}{l}\text { Perceptions } \\
\text { behaviour } \\
\text { change }\end{array}$ & $\begin{array}{l}\text { - Learning transferred from educational setting to } \\
\text { real life? } \\
\text { - On-the-job application of what has been learned? } \\
\text { - Changes in organisational safety culture? }\end{array}$ & \multicolumn{2}{|l|}{$\begin{array}{l}\text { - Self-report/auto-evaluation on confidence, behaviour and organisational change } \\
\text { (e.g. survey/questionnaires, semi-structured interviews, focus groups) }\end{array}$} & \\
\hline $3 b$ & Skill retention & - Retention of skills mastered? & \multicolumn{2}{|l|}{ - Repeat of skills tests used during training } & \\
\hline \multirow[t]{2}{*}{$3 \mathrm{c}$} & \multirow{2}{*}{$\begin{array}{l}\text { Change in } \\
\text { behaviour / } \\
\text { practice }\end{array}$} & - Team performance? & - Self-reports/auto-evaluation and other teamwork measurement tools & & \multirow{6}{*}{ 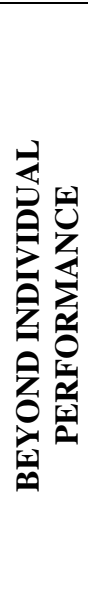 } \\
\hline & & $\begin{array}{l}\text { - Changes in clinical practice behaviour? } \\
\text { - Use of certain practices? }\end{array}$ & $\begin{array}{l}\text { - Changes in pattern of performing certain procedures } \\
\text { - Early recognition of potential problems }(\uparrow) \\
\text { - Referral patterns }(\uparrow)\end{array}$ & & \\
\hline 4 & OUTCOME & $\begin{array}{l}\text { Does training [and subsequent reinforcement] have } \\
\text { an impact? }\end{array}$ & & 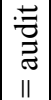 & \\
\hline $4 a$ & $\begin{array}{l}\text { Change in } \\
\text { organisation }\end{array}$ & $\begin{array}{l}\text { - Tangible results of programme? } \\
\text { - Impact on organisation? }\end{array}$ & $\begin{array}{l}\text { - Cost/return of income }(\downarrow) \\
\text { - Staff productivity }(\uparrow)\end{array}$ & 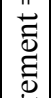 & \\
\hline $4 b$ & $\begin{array}{l}\text { Change in } \\
\text { quality of care } \\
\text { (processes) }\end{array}$ & $\begin{array}{l}\text { - Infrastructural changes? } \\
\text { - Services provided? } \\
\text { - Patient safety? } \\
\text { - Lowered risk? }\end{array}$ & $\begin{array}{l}\text { - Quality of care }(\uparrow) \\
\text { - Signal functions }(\uparrow) \\
\text { - Errors and litigation (malpractice claims) }(\downarrow) \\
\text { - Patient satisfaction( } \uparrow)\end{array}$ & 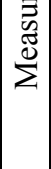 & \\
\hline $4 c$ & Benefits to patients & - Impact on measurable clinical outcome(s)? & - Patient outcome ( $\downarrow$ mortality, morbidity, adverse events) & & \\
\hline
\end{tabular}

* Measured at least $\geq 6$ months after last training session for any of the level-3 categories

Adapted from Fransen et al [76]; Grundy et al [78]' Haller et al [63]; Mirkuzie et al [68]; Pehrson et al [87]; Schaefer et al [88]; Sørensen et al [64]; Van Lonkhuijzen et al [14]; Vaux et al [89]; Yardley \& Dornan [85] 
Table 4. Different types of research questions.

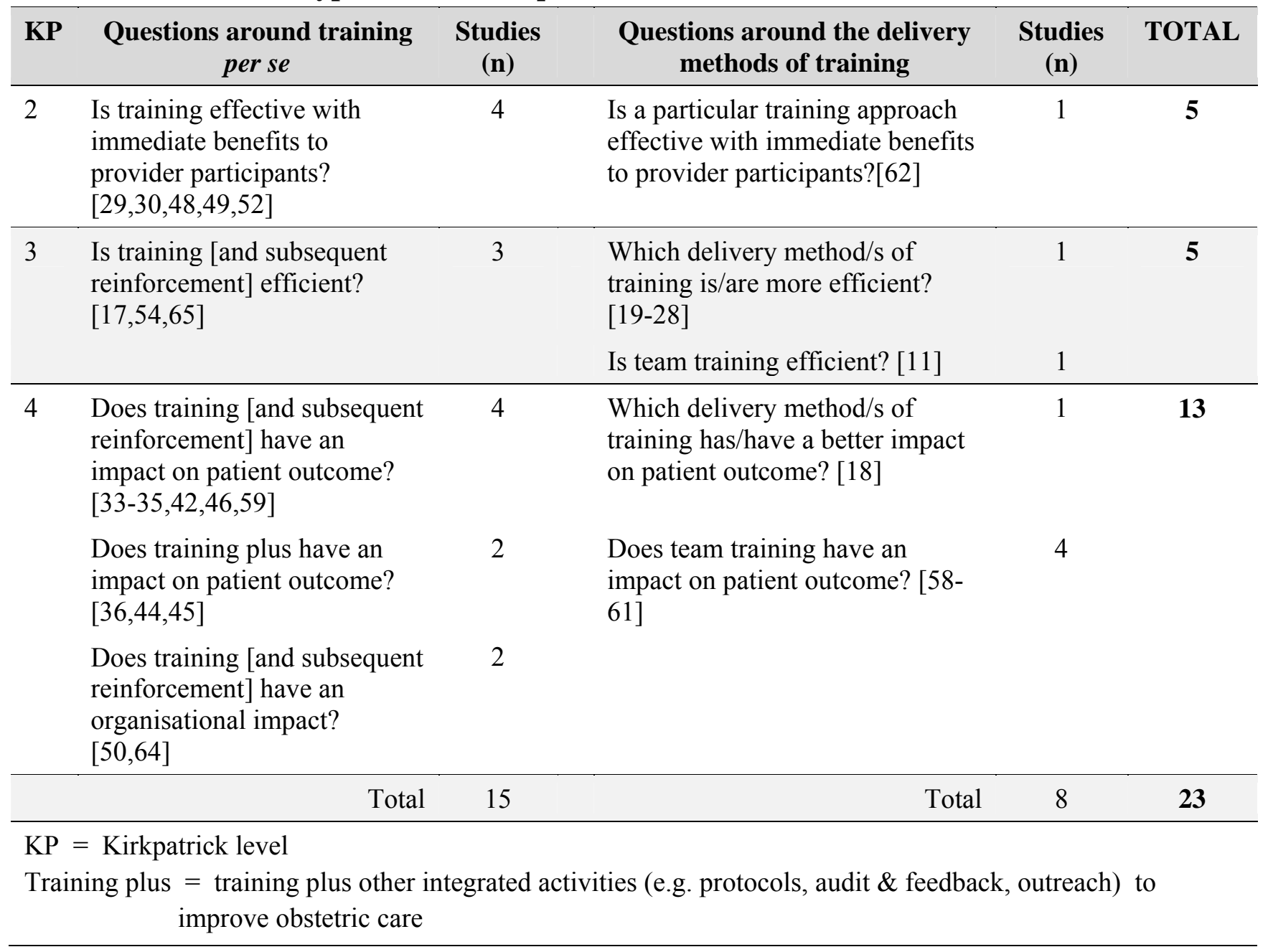


maternal and/or neonatal outcomes [19]. Table 3 gives a detailed description of the refined interpretation of the Kirkpatrick classification.

\section{ASSUMPTIONS ABOUT TRAINING}

The papers reviewed revealed three types of assumptions triggering study designs where training is central. Authors assumed that:

(1) It was not clear yet if training would have an effect on knowledge, skills, provider or organisational behaviour, or patient outcomes.

(2) Training had an effect on organisational or provider behaviour and patient outcomes. It was not clear if some forms of training would have a greater effect than others.

(3) Participants' clinical skills for obstetric emergencies were in place and did not necessarily need improvement. It was not always relevant how participants acquired/improved/updated their obstetric skills per se. However, there might be process and procedural errors that could influence patient outcome. It was not clear if these errors could be reduced with CRM types of training (with or without specific obstetric emergency simulations).

Based on the assumptions listed above two different sets of evaluation questions are implicitly posed about EmONC skill training - the first set of questions relates to training per se (regardless of choice of training method) and the second set of questions centres around the delivery methods of the training. Both these sets of questions can be categorised according to the Kirkpatrick levels 2 to 4 . Table 4 gives a list of questions researchers tried to answer. This table and the revised Kirkpatrick classification (Table 3) could also be used to 
reflect on possible gaps in research on training and whether there are or should be different research focuses for HICs and LMICs, respectively.

\section{IMPACT OF SKILL TRAINING IN EMERGENCY OBSTETRIC AND NEONATAL CARE}

The classification of each of the studies according to the revised Kirkpatrick model is depicted in Table 2. Ten studies reported on participants' reaction to training (level 1) and 13 studies on participant learning (level 2). Nine studies reported behaviour changes (level 3). Only the study by Crofts et al [20] that was part of the SaFE trial investigated skill retention six months and one year after training (level 3b). Four studies reported changes in behaviour or practice (level 3c) [17,34,35,54,57]. Thirteen studies had outcomes at level 4, of which 11 wanted to demonstrate the impact on patient outcome associated with training (level 4c).

Four studies reported the maternal and neonatal outcomes in a more holistic way by the use of an Adverse Outcomes Index (AOI) $[58,59,61]$ or a modified AOI [60] with weighted maternal and neonatal indicators or outcomes to measure the impact of a programme associated with training. The only RCT using a CRM approach did not show a significant difference in the AOI between the intervention and control hospitals, possibly because of the short time frame for conducting the trial and assessing the impact [58] or because it was not simulation based [79].

Most of the other studies included in the analysis reported on specific indicators or elements included in the AOI. With regard to infant outcomes, three studies reported, after training, a 
significant reduction in Apgar scores $<7$ at 5 minutes [33,44,57], whereas in the Australian PROMPT study the reduction was only significant at 1 minute [46]. Drayott and colleagues [33] reported a 50\% reduction in hypoxic-ischaemic encephalopathy (HIE) after training. Scholefield et al refer to a reduction of $50 \%$ in cord $\mathrm{pH}<7$ [44] and Shoushtarian et al to improved cord lactates [46]. Three studies reported on the decrease of birth trauma after training, one unspecified [60] and two on brachial plexus injury [34,44]. An abstract on an Americanised PROMPT study not included in our review also reported significant reductions in brachial plexus injuries and perinatal HIE [80]. The QUARITE trial could only demonstrate a significant decrease in neonatal mortality in hospitals in the capitals of Mali and Senegal [36]. In the same trial there was no effect on stillbirths [36], an observation also made in a UK study [33]. An abstract on the PRONTO study refers to a $44 \%$ reduction in perinatal mortality 8 months after training [31].

Less information is available on maternal outcomes after training. Two studies from Tanzania [12] and Kenya [57] observed a significant decrease in postpartum haemorrhage, although in the latter study there was no significant reduction in the case fatality rate [57]. In terms of a reduction in maternal mortality the QUARITE study documented a decrease in maternal deaths from haemorrhage, pre-eclampsia or eclampsia, and puerperal infection in the intervention group, but the mortality reduction was only significant in the capital hospitals and district hospitals, but not in regional hospitals [36]. The PRONTO trial reported a reduction of $68 \%$ in eclampsia 12 months after the intervention (abstract only) [31].

Some papers alluded to possible confounding factors that could have influenced the final results of a study on training $[11,33]$. Training does not take place in a vacuum and could have been accompanied by other clinical initiatives directly related to improving obstetric 
care in the form of continuous quality improvement and the introduction of clinicalgovernance interventions that some authors may not have mentioned. These activities could include: conducting regular in-service training in the form of refresher courses and/or emergency drills; drafting institutional goals; developing and using of protocols, guidelines, algorithms and checklists; improving information-technology use; running audits and conducting death reviews and/or monthly feedback meetings; doing outreaches; providing more support for staff involved in serious adverse events; practising active risk management; and improving incident reporting [33,36,44,45,29,81].

Training - if done properly [15] - contributes to behavioural changes with different endpoints for HICs and LMICs. In HICs, where many standard obstetric-care practices are assumed to be in place, the main focus is on reducing process errors for further improving patient safety, reducing morbidity and minimising litigation; hence the focus on CRM-based- and other forms of team training, with or without obstetric emergencies as application topics. In LMICs, there is a high demand for competency in EmONC [68]. Therefore, the training focus is on improving capacity and providing safe clinical skills to directly reduce maternal and neonatal mortality and morbidity.

\section{FUTURE AGENDA}

From the Kirkpatrick classification it can be concluded that sufficient evidence exists that EmONC skill training does make a difference, not only with regard to individual healthcare providers' knowledge, skills and attitudes, but also with regard to longer-term change in behaviour and an improvement in maternal and neonatal morbidity and mortality. Therefore, 
all health professionals providing maternal and neonatal care should have successfully completed an EmONC training course.

In terms of choice between training modalities and approaches the evidence points towards a preference for onsite training in the local 'in-house' environment using realistic, low-tech equipment for simulating obstetric emergencies. Advantages of this choice are cost and coverage - it is a cheaper package and more staff members are reached $[15,45]$. The point of departure should be multi-professional / interdisciplinary-teamwork training that is directly applicable to obstetric and perinatal emergencies and makes use of patient actors and appropriate simulation equipment [45]. A systematic review of team effectiveness found positive results for simulation training, CRM training, team-based training and continuous quality improvement initiatives [77]. Nyamtema et al [69] found that single interventions (e.g. training without improvement in services) did not really make a difference in the reduction of maternal mortality in resource-limited countries and the authors recommend the integration of interventional programmes. Training on its own may therefore not always change practice or have the desired effect [45]. Institutions and health authorities should investigate simple ways of how best to integrate other context-specific initiatives into a multifaceted training package or design a multiple-intervention package that has the potential of measuring the effect of their training activities at Kirkpatrick's levels 3 and 4.

Scaling up a training package across a health system beyond the original limited number of testing sites and maintaining the same high quality required for a scientific study remains problematic for both HICs and LMICs $[82,83]$. Ni Bhuinneain and McCarthy refer to a possible short-term Hawthorne effect with unsustainable outcomes on a larger scale [70]. Policies enabling or supporting the implementation of EMONC training packages are 
essential $[33,50,69,83]$, as well as supportive work environments and across-the-board participation at all levels of the health system [39]. Choosing realistic low-tech training equipment may facilitate onsite training because of a more equal distribution of available resources that can enable more appropriate training for a greater number of healthcare workers. Furthermore, a balance has to be found between what Dixon-Woods et al call “externally and internally initiated improvement efforts" (p. 878) [82]. In LMICs most BEmONC and CEmONC training is donor funded with little follow up on quality of training and supportive supervision. Donor agencies tend to fund short-term, fast-tracked interventions with a "quick impact" that often run parallel to a country's health system [84]. There is little evidence of internally initiated efforts of embedding training packages in the health system as part of normal in-service training and practice. The impact of training would be limited if essential resources at various levels are not allocated appropriately $[45,83]$ and training is not embedded in a multifaceted training package that aligns with a broader patient safety agenda.

Sustainability is another essential condition to be met when regular EmONC training is introduced at institutional or health-systems level [61]. Most papers reviewed were limited to short-term results of impact. EmONC training and death reviews should be included as a fixed item in a health system's budget and appropriate human resources should be allocated to develop the necessary leadership to sustain the initiative $[10,44,69]$. Investigation into the cost of different training packages may be needed $[15,70,79]$, especially in resource-limited settings [69]. Regulatory frameworks, legislation for certification of maternity centres or institutions, and discounts on indemnity-insurance premiums of facilities performing EmONC skills training could contribute to institutionalising such training. In planning a training package quality assurance and monitoring and evaluation mechanisms should be 
built-in features. According to Grady et al, lack of clarity on EmONC content, fragmentation and ad hoc delivery of training, and the absence of proper post-training follow up characterise many LSS-types of training in LMICs [49]. Some form of oversight of locally developed training packages by a higher or national body is one way of addressing variability in quality of training [15].

At institutional level, regular 'in-house' refresher training sessions that include emergency drills have been shown to be effective for maintaining quality of care over time and for orientating new staff members. However, it can be challenging to coordinate in busy maternity units $[15,45,79]$. Of importance is to build in accountability measures to ensure that these training sessions take place. Organisation of regular in-service training in emergency obstetric and neonatal care could, for example, be a key performance area for managers at various levels. Other questions revolve around the optimal interval between training sessions [26] and staff coverage. In the UK, annual obstetric skills training is required, a recommendation endorsed by the SaFE study [20]. In the Bristol study at Southmead Hospital, where the association between training and improved clinical outcomes was first demonstrated, more than $99 \%$ of staff had attended the training [33]. The SaFE study, however, noted variations in staff attendance of sessions after initial training that could possibly be related to staff members' levels of knowledge, skills and motivation, with the less skilled feeling less confident to attend [20]. Measures to monitor and ensure mandatory attendance of refresher training sessions should therefore be in place (e.g. a central training database as part of risk management) [45], as well as additional developmental sessions for staff members who are not yet proficient in certain skills despite training. To maximise individual participation, institution-level incentives [45] such as continuing professional 
development points, certification and premium discounts on indemnity insurance is an option to consider.

This review was limited to the research agenda in countries whose EmONC training initiatives had been reported in the English scientific literature. A broader review that also includes studies reported in other languages and a wider search of grey literature may yield additional insights to refine some of the recommendations provided above. Some areas for research that deserve more attention are: the necessity or not of having different research agendas for HICs and LMICs; scaling up EmONC training packages; the ideal measurement timeline between the introduction of an EmONC training package and the measurement of outcomes; the feasibility of using surrogate markers - and which markers - for measuring behaviour change and impact where longitudinal studies are not possible; the minimum number of emergency drills healthcare providers need to participate in per year to be sufficiently skilled to do conduct all the basic individual emergency procedures and to work efficiently in a team; onsite in-service training needs of inexperienced versus experienced providers [9]; reasons for individual non-participation in in-service training sessions [20]; and assessments that improve staff participation and performance [45]. The research agendas proposed by other papers in this issue highlight further areas of research in EmONC training $[12,53,72]$. Moving beyond the question of "Does the training work?" to questions such as "How does the training work?" and "Why does the training work?" may provide the necessary scope for expanding the research agenda $[75,85]$. It may be necessary to move beyond the outcome-based Kirkpatrick model of evaluating training to come to "insight into the underlying mechanisms that hinder or enable the achievement of higher-level program outcomes" (p. 1389) [86]. 


\section{SUMMARY}

EmONC training works and can improve quality of life and save lives. All health facilities providing maternity services should implement and sustain an EmONC training programme as a standard of care. All health professionals should be included in initial EmONC training courses and should undergo regular mandatory in-service training that includes emergency drills. Sufficient evidence exists to justify this expense and effort, which should be supported at all levels of the health system - from the Ministry of Health to individual institutions.

Team training and emergency drills are proven methods of delivering emergency obstetric and neonatal care skill training. Scaling up training packages should be a priority in all countries. Further evaluation research on the effect of training packages needs to think 'out of the box' beyond the current Kirkpatrick paradigm.

\section{Conflict of interest}

The authors of this chapter have no conflicts of interest to report.

\section{Acknowledgements}

The authors would like to acknowledge the support of the Medical Research Council of South Africa and the University of Pretoria. The views expressed are those of the authors. The editorial support of Barbara English (Office of the Deputy Dean: Research, Faculty of Health Sciences, University of Pretoria) is acknowledged with thanks.

\section{Online tables:}

Supplementary file 1 - Search flow

Supplementary file 2 - Detailed data from each study 


\section{REFERENCES}

[1] Hogan MC, Kyle JF, Naghavi M, Ahn YS, Wang M, Makela SM, et al. Maternal mortality for 181 countries, 1980-2008: a systematic analysis of progress towards Millennium Developmental Goal 5. Lancet. 2010;375(9726):1609-23.

[2] Souza JP, Tunçalp Ö, Vogel JP, Bohren M, Widmer M, Oladapo OT, et al. Obstetric transition: the pathway towards ending preventable maternal deaths. BJOG. 2014;212(Suppl 1):1-4.

[3] World Health Organization, UNICEF, United Nations Population Fund (UNFPA), World Bank, Division UNP. Trends in maternal mortality: 1990 to 2013. Estimates by WHO, UNICEF, UNFPA, The World Bank and the United Nations Population Division. Geneva: World Health Organization; 2014.

[4] World Health Organization, UNICEF. Countdown to 2015. Maternal, newborn and child survival. Fulfilling the health agenda for women and children. The 2014 report [conference draft]. Geneva: WHO; 2014 [cited 2014, June 30]. Available from: http://www.countdown2015mnch.org/documents/2014Report/Countdown_to_2015Fulfilling\%20the\%20Health_Agenda_for_Women_and_Children-The_2014_ReportConference_Draft.pdf.

[5] African Union. Status report on maternal newborn and child health; 2013 [cited 2014, June 30]. Available from: http://www.healthynewbornnetwork.org/sites/default/files/resources/MNCH\%202013 .pdf. 
[6] World Health Organization. Every Newborn: an action plan to end preventable deaths. Geneva: World Health Organization; 2014.

[7] Lewis G, editor. The Confidential Enquiry into Maternal and Child Health (CEMACH). Saving mothers' lives: reviewing maternal deaths to make motherhood safer - 2003-2005. The seventh report of the Confidential Enquiries into Maternal Deaths in the United Kingdom. London: CEMACH; 2007.

[8] Joint Commission on Accreditation of Healthcare Organizations. Preventing infant death and injury during delivery (Sentinel Event Alert Issue \#30) 21 July 2004 [cited 2015, January 20]. Available from: http://www.jointcommission.org/assets/1/18/SEA_30.PDF.

[9] Daniels K, Arafeh J, Clark A, Waller S, Druzin M, Chueh J. Prospective randomized trial of simulation versus didactic teaching for obstetrical emergencies. Simulation Healthc. 2010;5(1):40-5.

*[10] Siassakos D, Fox R, Bristowe K, Angouri J, Hambly H, Robson L, et al. What makes maternity teams effective and safe? Lessons from a series of research on teamwork, leadership and team training. Acta Obst Gynecol Scand. 2013;92(11):1239-43.

[11] Haller G, Garnerin P, Morales M-A, Pfister R, Berner M, Irion O, et al. Effect of crew resource management training in a multidisciplinary obstetrical setting. Int J Qual Health Care. 2008;20(4):254-63.

[12] Siassakos D. Team training for safer birth. Best Pract Res Clin Obstet Gynaecol. $2015 ; 29(8)$

[13] Siassakos D, Crofts J, Winter C, Draycott T. Multi professional fire drill training in the labour ward. Obstetrician Gynaecologist. 2009;11:55-60. 
*[14] Van Lonkhuizen L, Dijkman A, Van Roosmalen J, Zeeman G, Scherpbier A. A systematic review of the effectiveness of training in emergency obstetric care in lowresource environments. BJOG. 2010;117:777-87.

*[15] Black RS, Brocklehurst P. A systematic review of training in acute obstetric emergencies. BJOG. 2003;110(9):837-41.

[16] Beasley JW, Damos JR, Roberts RG, Nesbitt TS. The Advanced Life Support in Obstetrics course. A national program to enhance obstetric emergency skills and to support maternity care practice. Arch Fam Med. 1994;3(12):1037-41.

[17] Makuwani AM, Massawe SN, Mpembeni R, Shekimweri A. Setting an emergency obstetric care unit local initiatives, availability of resources and good will are the main ingredients of success: a lesson from Mkuranga District Hospital, Tanzania. East Afr J Public Health. 2010;7(2):109-13.

*[18] Riley W, Davis S, Miller K, Hansen H, Sainfort F, Sweet R. Didactic and simulation nontechnical skills team training to improve perinatal patient outcomes in a community hospital. Jt Comm J Qual Patient Saf. 2011;37(8):357-64.

[19] Crofts JF, Ellis D, Draycott TJ, Winter C, Hunt LP, Akande VA. Change in knowledge of midwives and obstetricians following obstetric emergency training: a randomised controlled trial of local hospital, simulation centre and teamwork training. BJOG. 2007;114(12):1534-41.

[20] Crofts JF, Fox R, Draycott TJ, Winter C, Hunt LP, Akande VA. Retention of factual knowledge after practical training for intrapartum emergencies. Int J Gynaecol Obstet. 2013;123(1):81-5.

[21] Crofts JF, Bartlet C, Ellis D, Winter C, Donald F, Hunt LP, et al. Patient-actor perception of care: a comparison of obstetric emergency training using manikins and patient actors. Qual Health Care 2008;17:20-4. 
[22] Siassakos D, Bristowe K, Hambly H, Angouri J, Crofts JF, Winter C, et al. Team communication with patient actors: findings from a multisite simulation study. Simulation Healthc. 2011;6(3):143-9.

*[23] Ellis D, Crofts JF, Hunt LP, Read M, Fox R, James M. Hospital, simulation center, and teamwork training for eclampsia management: a randomized controlled trial. Obstet Gynecol 2008;111:723-31.

[24] Siassakos D, Bristowe K, Draycott TJ, Angouri J, Hambly H, Winter C, et al. Clinical efficiency in a simulated emergency and relationship to team behaviours: a multisite cross-sectional study. BJOG. 2011;118(5):596-607.

[25] Crofts JF, Bartlett C, Ellis D, Hunt LP, Fox R, Draycott TJ. Training for shoulder dystocia: a trial of simulation using low-fidelity and high-fidelity mannequins. Obstet Gynecol. 2006;108(6):1477-85.

[26] Crofts JF, Bartlett C, Ellis D, Hunt LP, Fox R, Draycott TJ. Management of shoulder dystocia: skill retention 6 and 12 months after training. Obstet Gynecol. 2007;110(5):1069-74.

[27] Crofts JF, Ellis D, James M, Hunt LP, Fox R, Draycott TJ. Pattern and degree of forces applied during simulation of shoulder dystocia. Am J Obstet Gynecol. 2007;197(2):156.e1-156.e6.

[28] Siassakos D, Fox R, Crofts JF, Hunt LP, Winter C, T.J. D. The management of a simulated emergency: better teamwork, better performance. Resuscitation. 2011;82:203-6.

[29] Walker DM, Cohen SR, Estrada F, Monterroso ME, Jenny A, Fritz J, et al. PRONTO training for obstetric and neonatal emergencies in Mexico. Int J GynaecolObstet. $2012 ; 116(2): 128-33$ 
*[30] Walker D, Cohen S, Fritz J, Olvera M, Lamadrid-Figueroa H, Cowan J, et al. Team training in obstetric and neonatal emergencies using highly realistic simulation in Mexico: impact on process indicators. BMC Pregnancy Childbirth. 2014;14:367.

[31] Walker D, Fritz J, Olvera M, Lamadrid H, Cohen S, Fahey J. PRONTO Low-tech obstetric simulation and team training in Mexico improves patient outcomes, and evidence-based care at birth. Obstet Gynecol. 2014;123(Suppl 1):176s-7s.

[32] Walker D, Cohen S, Fritz J, Olvera M, Lamadrid H, Carranza L. PRONTO Low-tech obstetric simulation and team-training for obstetric and neonatal emergencies in Mexico leads to a decrease in cesarean delivery rates. Obstet Gynecol. 2014;123(Suppl 1):177S.

*[33] Draycott T, Sibanda T, Owen L, Akande V, Winter C, Reading S, et al. Does training in obstetric emergencies improve neonatal outcome? BJOG. 2006;113:177-82.

[34] Draycott TJ, Crofts JF, Ash JP, Wilson LV, Yard E, Sibanda T, et al. Improving neonatal outcome through practical shoulder dystocia training. Obstet Gynecol 2008;112:14-20.

[35] Siassakos D, Hasafa Z, Sibanda T, Fox R, Donald F, Winter C, et al. Retrospective cohort study of diagnosis-delivery interval with umbilical cord prolapse: the effect of team training. BJOG. 2009;116:1089-96.

*[36] Dumont A, Fournier P, Abrahamowicz M, Traore M, Haddad S, Fraser WD. Quality of care, risk management, and technology in obstetrics to reduce hospital-based maternal mortality in Senegal and Mali (QUARITE): a cluster-randomised trial. Lancet. 2013;382(9887):146-57.

[37] Johanson R, Cox C, O'Donnell E, Grady K, Howell C, Jones P. Managing obstetric emergencies and trauma (MOET): structured skills training using models and realitybased scenarios. Obstetrician Gynaecologist 1999;1(2):46-52. 
[38] Johanson R, Akhtar S, Edwards C, Dewan F, Haque Y, Jones P, et al. MOET: Bangladesh - an initial experience. J Obstet Gynaecol Res. 2002;28:217-23.

[39] Johanson RB, Menon V, Burns E, Kargramanya E, Osipov V, Israelyan M, et al. Managing Obstetric Emergencies and Trauma (MOET) structured skills training in Armenia, utilising models and reality based scenarios. BMC Med Educ. 2002;2:5.

[40] Bower DJ, Wolkomir MS, Schubot DB. The effects of the ALSO course as an educational intervention for residents. Fam Med. 1997;29(3):187-93.

[41] Taylor HA, Kiser WR. Reported comfort with obstetrical emergencies before and after participation in the Advanced Life Support in Obstetrics course. Fam Med. 1998;30(2):103-7.

[42] Sorensen BJ, Rasch V, Massawe S, Nyakina J, Elsass P, Nielsen BB. Advanced Life Support in Obstetrics (ALSO) and post-partum hemorrhage: a prospective intervention study in Tanzania. Acta Obst Gynecol Scand 2011;90:609-14.

[43] Draycott T. Practical obstetric multi-professional training - PROMPT. The Health Foundation, May 2013.

[44] Scholefield H. Embedding quality improvement and patient safety at Liverpool Women's NHS Foundation Trust. Best Pract Res Clin Obstet Gynaecol 2007;21:593607.

*[45] Siassakos D, Crofts JF, Winter C, Weiner CP, Draycott TJ. The active components of effective training in obstetric emergencies. BJOG. 2009;116(8):1028-32.

[46] Shoushtarian M, Barnett M, McMahon F, Ferris J. Impact of introducing Practical Obstetric Multi-Professional Training (PROMPT) into maternity units in Victoria, Australia. BJOG. 2014;121(13):1710-8. 
[47] Liverpool School of Tropical Medicine. CMNH International Conference on Maternal and Newborn Health 2014 [cited 2014, October 2]. Available from: http://www.mnhu.org/media/15009/cmnh-conference-2014.pdf.

[48] Van Lonkhuijzen L, Ameh C, Mdegela M, Hulsbergen M, Stekelenburg J, van den Broek N. Life Saving Skills: Essential Obstetric and Newborn Care training in Tanzania. Ned Tijdschr Obst Gynaecol. 2008;121:159-61.

[49] Grady K, Ameh C, Adegoke A, Kongnyuy E, Dornan J, Falconer T. Improving essential obstetric and newborn care in resource-poor countries. J Obstet Gynaecol. 2011;31(1):18-23.

[50] Ameh C, Adegoke A, Hofman J, Ismail FM, Ahmed FM, Van den Broek N. The impact of emergency obstetric care training in Somaliland, Somalia. Int J Gynaecol Obstet. 2012;117(3):283-7.

[51] Frank K, Lombaard H, Pattinson RC. Does completion of the Essential Steps in Managing Obstetric Emergencies training package improve knowledge and skills in managing obstetric emergencies? SAJOG. 2009;13(3):94-9.

[52] Raven J, Utz B, Roberts D, van den Broek N. The 'Making it Happen' programme in India and Bangladesh. BJOG. 2011;118 Suppl 2:100-3.

[53] Van den Broek N. Making it happen - lessons in training in low and middle income countries. Best Pract Res Clin Obstet Gynaecol. 2015;29(8)

[54] Sloan NL, Nguyen TN, Do TH, Quimby C, Winikoff B, Fassihian G. Effectiveness of lifesaving skills training and improving institutional emergency obstetric care readiness in Lam Dong, Vietnam. J Midwifery Womens Health 2005;50:315-23. 
[55] Lalonde AB, Beaudoin F, Smith J, Plourde S. The ALARM international program: a mobilizing and capacity-building tool to reduce maternal and newborn mortality and morbidity worldwide. J Obstet Gynaecol Can. 2006;28(11):1004-8.

[56] Dumont A, Fournier P, Abrahamowicz M, Traoré M, Haddad S, Fraser WD, et al. Quality of care, risk management, and technology in obstetrics to reduce hospitalbased maternal mortality in Senegal and Mali (QUARITE): a cluster-randomised trial. Lancet. 2013;382(9887):146-57.

[57] Spitzer RF, Steele SJ, Caloia D, Thorne J, Bocking AD, Christoffersen-Deb A, et al. One-year evaluation of the impact of an emergency obstetric and neonatal care training program in Western Kenya. Int J Gynaecol Obstet. 2014;127(2):189-93.

*[58] Nielsen PE, Goldman MB, Mann S, Shapiro DE, Marcus RG, Pratt SD, et al. Effects of teamwork training on adverse outcomes and process of care in labour and delivery: a randomized controlled trial. Obstet Gynecol 2007;109:48-55.

[59] Pratt S, Mann S, Salisbury M, Greenberg P, Marcus R, Stabile B, et al. Impact of CRM-based team training on obstetric outcomes and clinicians' patient safety attitudes. Int Comm J Qual Patient Saf 2007;33:720-5.

[60] Wagner B, Meirowitz N, Shah J, Nanda D, Reggio L, Cohen P, et al. Comprehensive perinatal safety initiative to reduce adverse obstetric events. J Healthc Qual. 2012;34(1):6-15.

[61] Phipps MG, Lindquist DG, McConaughey E, O’Brien JA, Raker CA, Paglia MJ. Outcomes from a labour and delivery team training program with simulation component. Am J Obstet Gynecol 2012;206:3-9.

[62] Robertson B, Schumacher L, Gosman G, Kanfer R, Kelley M, DeVita M. Simulationbased crisis team training for multidisciplinary obstetric providers. Simulation Healthc. 2009;4(2):77-83. 
[63] Haller G, Garnerin P, Morales M-A, Pfister R, Berner M, Irion O, et al. Effect of crew resource management training in a multidisciplinary obstetrical setting. Int J Qual Health Care. 2008;20(4):254-63.

[64] Sørensen JL, Løkkegaard E, Johansen M, Ringsted C, Kreiner S, McAleer S. The implementation and evaluation of a mandatory multi-professional obstetric skills training program. Acta Obst Gynecol Scand. 2009;88(10):1107-17.

[65] Reynolds A, Ayres-de-Camposa D, Lobo M. Self-perceived impact of simulationbased training on the management of real-life obstetrical emergencies. Eur J Obstet Gynecol Reprod Biol. 2011;159(1):72-6.

[66] World Health Organization. Managing complications in pregnancy and childbirth: a guide for midwives and doctors. Geneva: World Health Organization; 2000.

[67] World Health Organization. Pregnancy, childbirth, postpartum and newborn care: a guide for essential practice. Geneva: World Health Organization; 2006.

[68] Mirkuzie AH, Sisay MM, Bedane MM. Standard basic emergency obstetric and neonatal care training in Addis Ababa; trainees reaction and knowledge acquisition. BMC Med Educ. 2014;14:201.

[69] Nyamtema AS, Urassa DP, Van Roosmalen J. Maternal health interventions in resource limited countries: a systematic review of packages, impacts and factors for change. BMC Pregnancy Childbirth. 2011;11:30.

[70] Ni Bhuinneain GM, McCarthy FP. A systematic review of essential obstetric and newborn care capacity building in rural sub-Saharan Africa. BJOG. 2015;122:174-82.

[71] Curet LB, Foster-Rosales A, Hale R, Kestler E, Medina C, Altamirano L, et al. FIGO Save the Mothers Initiative: the Central America and USA collaboration. Int Gynaecol Obstet. 2003;80(2):213-21. 
[72] Draycott T. PROMPT...fire drills. Best Pract Res Clin Obstet Gynaecol. $2015 ; 29(8)$

[73] Kirkpatrick D. Evaluating training programs: the four levels. 2nd ed. San Francisco, CA: Berrett-Kochler Publishers; 1998.

[74] Frye AW, Hemmer PA. Program evaluation models and related theories: AMEE Guide No. 67. Med Teach. 2012;34:e288-e99.

[75] Haji F, Morin M-P, Parker K. Rethinking programme evaluation in health professions education: beyond 'did it work?'. Med Educ. 2013;47:342-51.

[76] Fransen AF, Van de Ven J, Merien AER, De Wit-Zuurendonk LD, Houterman S, Mol BW, et al. Effect of obstetric team training on team performance and medical technical skills: a randomised controlled trial. BJOG. 2012;119:1387-93.

[77] Buljac-Samardzic M, Dekker-van Doorn CM, Van Wijngaarden JDH, Van Wijk KP. Interventions to improve team effectiveness: a systematic review. Health Policy. 2010;94:183-95.

[78] Gundry R, Siassakos D, Crofts JF, Draycott TJ. Simulation training for obstetric procedures and emergencies. Fetal Matern Med Rev. 2010;21(4):323-56.

[79] Merién AER, Van de Ven J, Mol BW, Houterman S, Oei SG. Multidisciplinary team training in a simulation setting for acute obstetric emergencies: a systematic review. Obstet Gynecol. 2010;115:1021-31.

[80] Weiner C, Samuelson L, Collins L, Satterwhite C. 5-year experience with PROMP (PRactical Obstetric Multidisciplinary Training) reveals sustained and progressive improvements in obstetric outcomes at a US hospital. Am J Obstet Gynecol. 2014;210(1):S40.

[81] Pattinson R. Improving emergency obstetric care. Int J Gynecol Obstet $2010 ; 110(2): 87-8$. 
[82] Dixon-Woods M, McNicol S, Martin G. Ten challenges in improving quality in healthcare: lessons from the Health Foundation's programme evaluations and relevant literature. BMJ Qual Saf 2012;21:876-84.

[83] Bergh A-M, Allanson E, Pattinson RC. What is needed for taking emergency obstetric and neonatal programmes to scale? Best Pract Res Clin Obstet Gynaecol. $2015 ; 29(8)$

[84] Richard F, Hereat D, Ouedraogo C, Delvaux T, Samake S, Van Olmen J, et al. SubSaharan Africa and the health MDGs: the need to move beyond the "quick impact" model. Reprod Health Matters. 2011;19(38):42-55.

[85] Yardley S, Dornan T. Kirkpatrick's levels and education 'evidence'. Med Educ. 2012;46:97-106.

[86] Parker K, Burrows G, Nash H, Rosenblum ND. Going beyond Kirkpatrick in evaluating a clinician scientist program: it's not "If it works" but "How it works". Acad Med. 2011;86:1389-96.

[87] Pehrson C, Sorensen JL, Amer-Wåhlin I. Evaluation and impact of cardiotocography training programmes: a systematic review. BJOG. 2011;118:926-35.

[88] Schaefer JJ, Vanderbilt AA, Cason CL, Baumann EB, Glavin RJ, Lee FW, et al. Literature review: instructional design and pedagogy science in healthcare simulation Simulation Healthc. 2011;6(7):S30-S41.

[89] Vaux E, Went S, Norris M, Ingham J. Learning to make a difference: introducing quality improvement methods to core medical trainees. Clin Med. 2012;12(6):520-5. 